Papers and Proceedings of the Royal Society of Tasmania, Volume 113, 1979.

(m5. received 9.8 .1978 )

\title{
SKELETAL REMAINS AT CONINGHAM, TASMANIA, AUSTRALIA
}

by Alan Wallace and Jim Stockton

University of Tasmania and National Parks and Wildlife Service, Tasmania

(with one table and four plates)

\author{
ABSTRACT
}

WALLACE, A. and STOCKTON, J., 1979 (20 vii): Skeletal remains at Coningham, Tasmania, Australia. Pap. Proc. R. Soe. Tasm., 113: 149-153 (inc1. four plates). ISSN 0080-4703. Department of Anatomy, University of Tasmania, Hobart, 'Tasmania and National Parks and Wildlife Service, Magnet Court, Sandy Bay, Tasmania, Australia.

Human bones, including a well-preserved skull, have been excavated from an Aboriginal midden exposed by erosion at Coningham, Tasmania in 1976. Associated charcoal has been C14 dated $840 \pm 95$ years BP.

\section{INTRODUCTION}

In February 1976 an alert holidaymaker observed human bones eroding from a bank at Coningham, a sandy cove $25 \mathrm{~km}$ south of Hobart. The bank is one metre high, immediately above the high-water mark and represents the seaward edge of open dry eucalypt forest sloping steeply to the foreshore. An area of fairly level ground at the site had been used for keeping a small boat, and such usage had possibly destabilised the earth. Following the collection of exposed bones, work was halted, and the site later carefully excavated by one of us (J.S.).

\section{SITE DESCRIPTION}

The site was of shell midden covered by grass (Tasmanian Aboriginal Sites Index Card 126). It was divided into arbitrary 1 metre-square grid units, and attempts were made during excavation to follow the depositional stratigraphy. This proved impracticable and was discontinued. The site was then excavated in arbitrary spits. Finds were pedestalled and plotted before removal, but the skeletal material had an oddly confused distribution. A charcoal sample was collected from amongst the bones and submitted for radiocarbon analysis (SUA-626). This yielded a date of $840 \pm 95$ years BP.

The main she11 present in the midden was Ostrea angasi (mud-oyster) and lesser amounts of Mytilus planulatus (musse1). Individuals of the scallop family Pecten meridionalis were also found in the deposit. These have been rare in other sites examined in the D'Entrecasteaux Channel area. One Ostrea shell had a central hole in it, but this may have been due to natural causes.

At the horizon of densest bone concentration two arcs of Ostrea angasi shells were standing on edge. This was unusual as most of these large shells lay flat in the deposit. No implements or ochre were recovered from the site.

The occupation sequence for the site appears to have started after the Holocene sea-level rise, but as no bottom radiocarbon date has been made on the deposit, it is impossible to give an accurate indication of the basal date. At first a typical low energy system marine midden accumulated on the bank above the beach. Then an unburnt body, still more or less intact, was left on the site of the midden. There is no conclusive sign of burning of the bones or of a hearth associated with the bones.

Similarly, there is no sign of a pit having been dug into the deposit into which? 

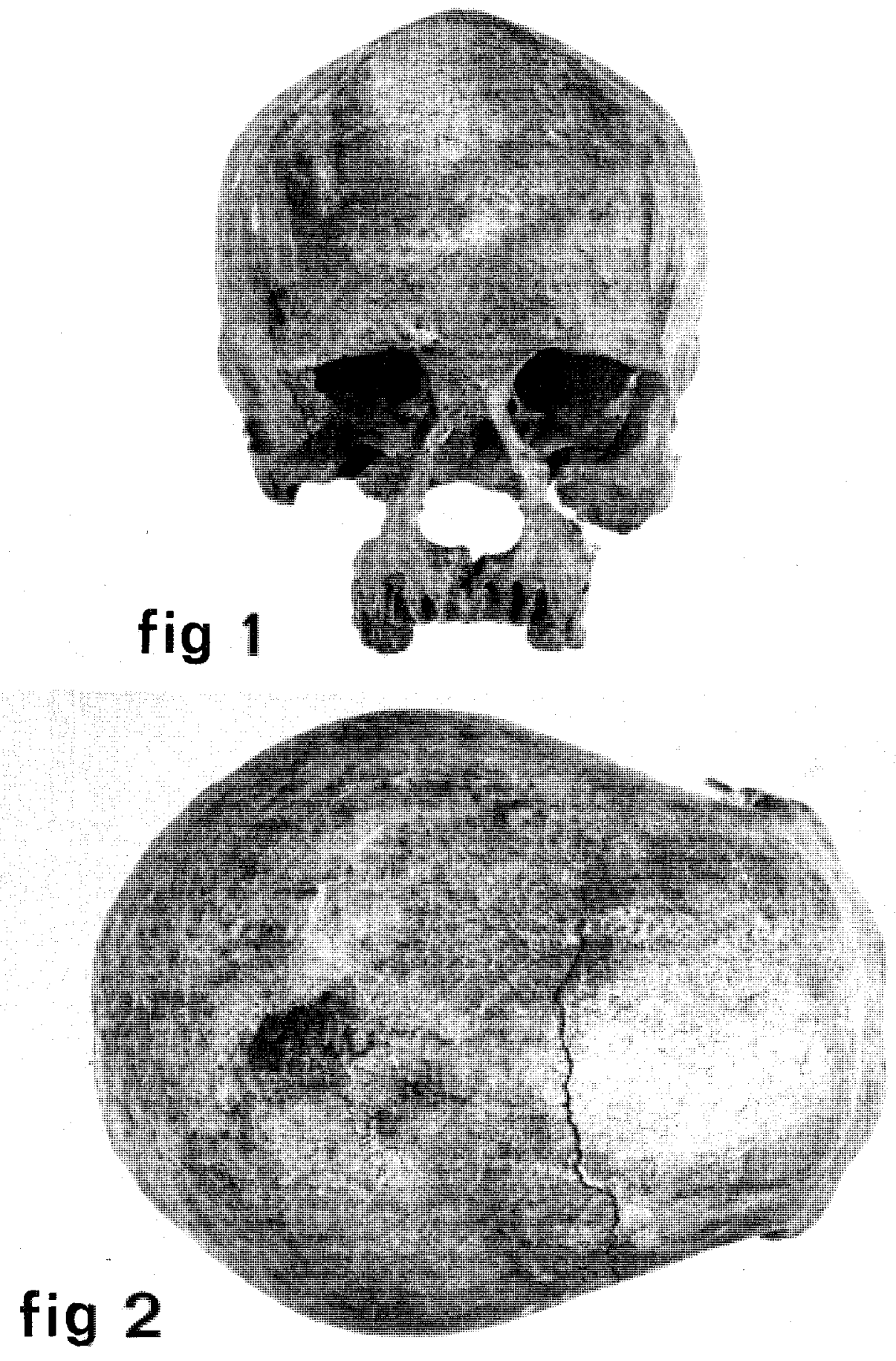
Alan Wallace and Jim Stockton
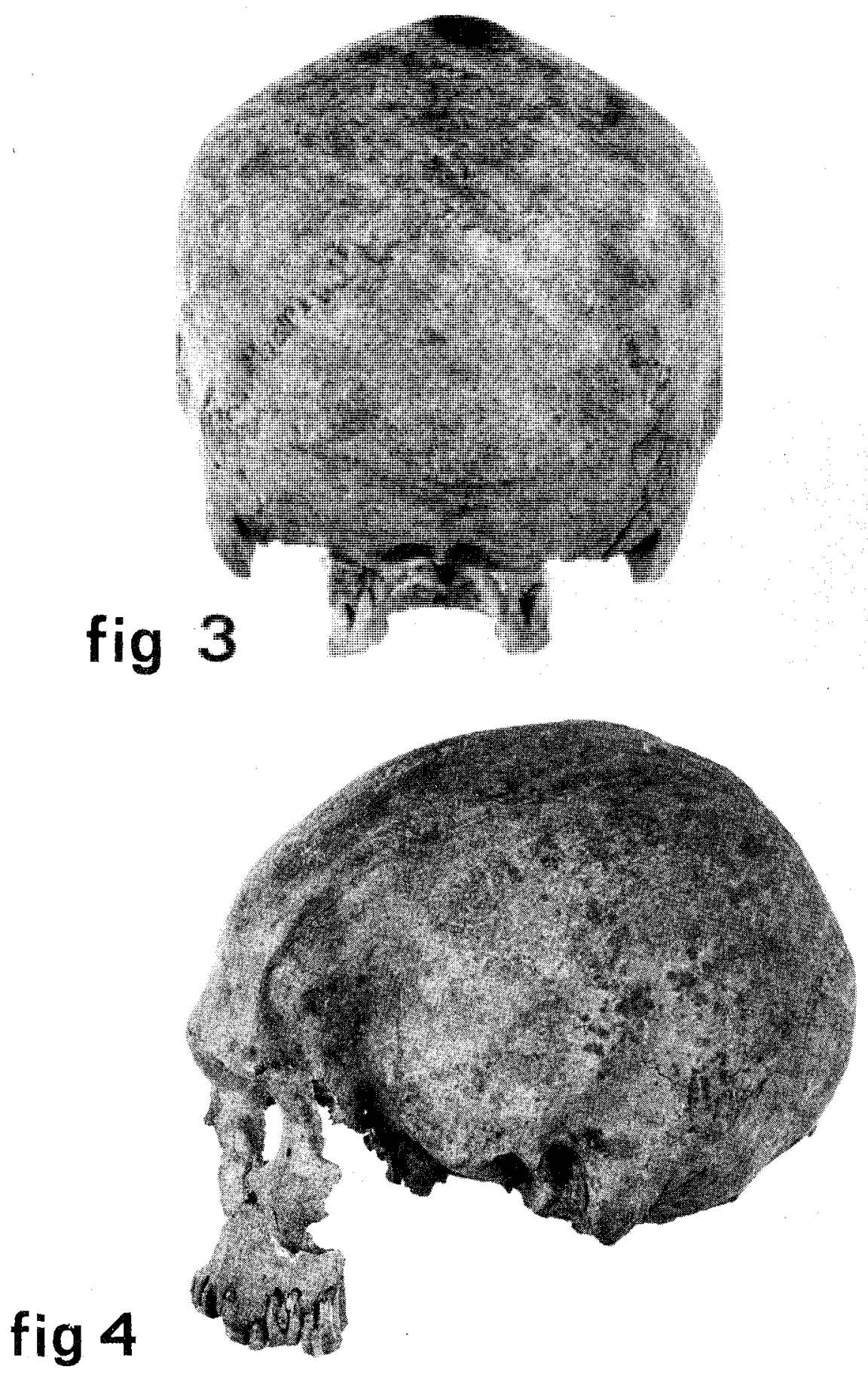
body or bones were placed. The corpse was then probably disturbed by carnivores, leading to a breaking up of long bones and a rearrangement of bone fragments. The bones were then gradually covered by aeolian sand blowing up from the beach. Such a process still continues and the soil level is aggrading.

In recent years the sea has begun to erode the bank on which the midden and skeletal material rests. Part of the skull eroded out, and its recognition led to the salvage excavation of the remaining material.

\section{GENERAL DESCRIPTION OF SKELETAL REMAINS}

The bones have been acceded to the Tasmanian Museum and Art Gallery as M4301. The skull was largely intact, with the exception of the facial skeleton which was fragmented and incomplete. Much reconstruction of the left orbital margin has been. possible, together with the anterior maxillary region, including part of the nasal area.

Measurements are given in Table 1 , and Plates 1 to 4 depict the skul1 in normae frontalis, verticalis, occipitalis and lateralis. The shape of skull is sphenoid and phaenozygous in normae verticalis. Prominent superciliary ridges are present with a moderately marked (Broca grade III) glabella. There is a supraglabellar fossa extending laterally into a shallow ophrionic groove. Zygomatic trigones are prominent and there is moderate post-orbital constriction. Temporal crests are sharp anteriorly, but fade away posteriorly. The forehead is sloping (frontal curvature index 21) and the vault of the skull is keel-shaped, particularly along a median parietal ridge running back from bregma. The sagittal suture does not lie in a groove, and the parietal bones slope straight out to moderate parietal bossing. Very marked supramastoid crests are present, whilst the mastoid processes themselves are of medium size. The orbits are rectangular and set somewhat obliquely. Considerable sutural obliteration on the vault of the skull suggests an age of death of 30 to 40 years. The sphenooccipital junction is not fully ossified, which would have indicated a much younger age, but the bone in this region is damaged and such interpretation dubious.

The maxilla and palate are incomplete and several teeth have been lost postmortem; those remaining comprise all four upper premolars and the anterior two molars on each side $\left(\mathrm{M}^{1} \mathrm{M}^{2}\right)$. In the mandible only part of the first right premolar and the anterior two left molars were retrieved. There is a congenital absence of the third lower left molar (confj.rmed by X-ray). All the teeth are very heavily worn. There is moderate interproximal attrition and some possible evidence of chronic peridontal disease but no evidence of caries.

The skull was sexed using Larnach and Freedman's (1964) system for sexing Aborigines from Coastal New South Wales by seven characteristics.

Values are as follows:

Feature

G1abe11a

Superciliary ridges

Zygomatic trigone

Malar tuberosity

Mastoid process

Occipital markings

Palate size

Total
Points

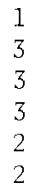

Unavailable and therefore given a mean score of 2

16

The total of 16 points designates a male. 
Alan Wallace and Jim Stockton

The right tibia lay in two fragments. When reconstructed it was $0.35 \mathrm{~m}$ in length. A hundred milimetres from its proximal end, and on the postero-medial surface a flake of bone is missing about $3 \mathrm{~cm}^{2}$ in area and with a maximal depth of $1 \mathrm{~mm}$. The deficiency is wedge-shaped, with a shallow lower section deepening to an abrupt upper border. There is no periosteal reaction and the bone is uniformily weathered. It is difficult to see how this damage could have been caused by any stone implement. It has more the appearance of being the work of a steel blade at or after death?

Using Pearson's modified table (after olivier) for estimating stature from male tibiae, an estimate of a height of $1.62 \mathrm{~m}$ is reached.

other post-cranial skeletal remnants comprise the shaft of the right femur and fragments of vertebrae, ulna bones, patellae and ribs. Much of the shaft of the right humerus is also preserved. There are fragments of both hips, each showing sufficient. of the sciatic notch to indicate its curvature and confirm masculinity. There is also a portion of a scaralised fifth lumbar vertebra.

The bones appear Aboriginal and fit into the accepted range of Tasmanian skeletons yet do not show any of the features that have been classically associated with Tasmanians (Wallace and Doran 1976). The presence of damage to the tibia seemingly due to a steel blade is cleariy an anachronism if the archaeological context is accepted and a date of 840 years BP. attributed. A possible explanation is that at some point in the last century the area has been partly dug and sonething like a spade or adze has sliced into the buried bone. The alternative is of course that the bones date to the post-contact period and represent an intrusion into the (dated) charcoal of the midden. Collagen dating of the bones is planned to clarify the problem.

TABLE 1

CRANIAL MEASUREMENTS AND INDICES

Measurement

Maximal cranial length

Maximal cranial breadth

Basi-bregmatic height

Basi-nasal length

Upper facial height

Basi-alveolar length

Nasal height (estimated)

Nasal breadth

Supra-orbital breadth

Minimal frontal breadth

(at fronto-sphenoid suture)

\section{Value in mm Measurement}

188

145

135

1.00

64

99

50

28

105

86
Orbital height $\quad 30$

Orbital breadth 40

Post-orbital constriction $\quad 19$

Frontal subtense 25

Frontal chord 119

Fronta1 curvature index 21

Cranial index 77

(mesocranial)

Orbital index

Cranial capacity (von Bonin formula)

Cranial capacity direct measurement
75

1373

1250

\section{REFERENCES}

Larnach, S.L. and Freedman, L., 1964: Sex determinations of Aboriginal crania from coastal New South Wales, Australia. Rec. Aust. Mus., 26(11): 295-308.

wallace, A.G. and Doran, G., 1976: Early Man in Tasmania - new skeletal evidence. In Kirk, R.L. and Thorne, A.G. (Eds): THE ORIGINS OF THE AUSTRALIANS. Aust. Inst. of Aboriginal stud., 173-182. 